\title{
Efficacy of Licorice on Salivary Streptococcus mutans Levels vs Chlorhexidine Mouthwash in High Caries Risk Patients: A Randomized Clinical Trial
}

\author{
Nancy Helmy ${ }^{1}$, Shereen Hafez ${ }^{2}$, Amira Farid ${ }^{3}$
}

\begin{abstract}
Aim: To evaluate the efficacy of an innovative herbal licorice mouthwash on reducing salivary Streptococcus mutans levels versus chlorhexidine mouthwash in high caries risk patients.

Methodology: A total number of 52 high caries risk patients were assigned to this study. Patients were randomly divided into two groups $(n=26)$ according to the type of mouthwash $(G)$ : Patients in group $G_{1}$ used the mouthwash containing chlorhexidine, while patients in group $G_{2}$ used the mouthwash containing the innovative licorice extract. Afterward, each group was further divided into three subgroups according to the time (T): $T_{0}$ represents the baseline, $T_{1}$ represents the time immediately after using the mouthwash, and $T_{2}$ represents the time 1 week after using the mouthwash. Furthermore, $\mathrm{pH}$ and plaque index were recorded. Data were statistically analyzed using a Chi-square test for categorical data, Shapiro-Wilk test for numerical data, and one-way repeated measures ANOVA followed by Bonferroni post hoc test for intragroup comparisons. The significance level was set at $p \leq 0.05$ for all tests. Statistical analysis was performed with IBM ${ }^{\otimes}$ SPSS $^{\circledR}$ Statistics version 26 for Windows.

Results: It was found that in high caries risk patients, there was no significant difference between licorice and chlorhexidine mouthwashes regarding Streptococcus bacterial count. Moreover, it was found that licorice mouthwash stimulates salivary flow, and thus, it raises salivary $\mathrm{pH}$ in patients with high caries risk. However, the plaque index of chlorhexidine showed better results. Additionally, there was a positive weak correlation between bacterial count and plaque index.

Conclusions: Licorice mouthwash may demonstrate a promising antibacterial effect that can be a suitable alternative for current synthetic mouthwashes.

Clinical significance: Natural herbal mouthwash could be incorporated in dental preventive measures and could be used as cavity-fighting compound. It introduces a minimal health hazard substitute for conventional synthetic preventive measures.

Keywords: Chlorhexidine mouthwash, Herbal licorice mouthwash, High caries index, Randomized clinical trial, Salivary Streptococcus mutans level. The Journal of Contemporary Dental Practice (2021): 10.5005/jp-journals-10024-3156
\end{abstract}

\section{INTRODUCTION}

Dental caries is a chronic, multifactorial, and biofilm-mediated disease, which is modulated by diet, yet it is preventable. Despite the improvements of preventive dentistry, the burden of dental caries remains highly unaccepted worldwide due to the global prevalence of $35 \%$ for all ages combined. ${ }^{1}$ According to the World Health Organization (WHO), the prevalence of dental caries in the Egyptian population reached $60 \% .^{2}$ The production of acids resulting from sugar metabolism by bacteria and the subsequent decrease in environmental $\mathrm{pH}$ are responsible for demineralization of the tooth surface and the formation of caries. Most of the clinical studies reported that Streptococcus mutans play a major role in dental caries because of their acid production. It has significant adherence in retentive areas on the tooth structure and deepens biofilm. Furthermore, it may produce a shift in the ecological system that leads to the emergence of acidogenic and aciduric organisms. ${ }^{3}$ Chlorhexidine is one of the most successful chemoprophylactic agents. It has antimicrobial activity against $S$. mutans and exhibits antiplaque and antigingivitis properties as well. Nonetheless, the use of chlorhexidine introduces several hazards that include teeth staining, altered taste sensation, vomiting, oral cytotoxicity, and increased risk of dental caries due to fermentation and alcohol content. ${ }^{4}$

Innovations and recent research in dentistry introduced herbal formulations created from natural products, such as cocoa, miswak, propolis, and licorice extract, which exhibited

\begin{abstract}
${ }^{1-3}$ Conservative Dentistry Department, Faculty of Dentistry, Cairo University, Cairo, Egypt

Corresponding Author: Nancy Helmy, Conservative Dentistry Department, Faculty of Dentistry, Cairo University, Cairo, Egypt, Phone: +2001206897557, e-mail: nancy.helmy@dentistry.cu.edu.eg

How to cite this article: Helmy N, Hafez S, Farid A. Efficacy of Licorice on Salivary Streptococcus mutans Levels vs Chlorhexidine Mouthwash in High Caries Risk Patients: A Randomized Clinical Trial. J Contemp Dent Pract 2021;22(8):914-921.
\end{abstract}

Source of support: Nil

Conflict of interest: None

anticaries effects. ${ }^{5}$ Although the anticariogenic properties of licorice have been suggested for over 30 years, however, few studies on this aspect have been published. Recent research suggested that licorice extracts and licorice bioactive ingredients, such as glabridin, licoricidin, licorisoflavan A, and glycyrrhizin, have potential beneficial effects in oral diseases. These effects have been associated with the antiadherence, antimicrobial, and anti-inflammatory properties of the compounds. ${ }^{6}$ The principal ingredient of licorice (Glycyrrhiza glabra L) is glycyrrhizin, which is the key therapeutic compound in licorice. It prevents the breakdown of adrenal hormones, such as cortisol, and this renders 
these hormones more accessible to the body; thus, glycyrrhizin acts as immunostimulant. ${ }^{7}$ Jain et al. $^{8}$ have reported that licorice extracts exert antimicrobial and cariostatic efficacy by stimulation of the salivary flow and increasing the buffering capacity of the saliva. Lollipops containing herbal licorice were recommended for high caries risk patients who did not follow with the oral hygiene measures as an alternative to cariogenic confectionery led to a diminution in salivary S. mutans in many studies. ${ }^{9}$ Moreover, licorice showed the effectiveness of a simple herbal caries-prevention protocol for reducing the salivary S. mutans levels in children. ${ }^{10}$ The antibacterial effects of licorice are driven by its ability to inhibit the glucosyltransferase activity of S. mutans, which is responsible for the formation of insoluble glucans in biofilm formation. ${ }^{11}$ There is a knowledge gap in validating the clinical effects of licorice oral rinse on the reduction of plaque, gingival inflammation, and reduction levels of S. mutans and controlling dental caries. Accordingly, this randomized clinical trial was proposed to evaluate the efficacy of innovative herbal licorice on reducing salivary S. mutans levels versus chlorhexidine mouthwash in high caries risk patients. The null hypothesis states that there will be no significant difference between preventive measure containing innovative licorice root extract and chlorhexidine preventive measure on salivary S. mutans count.

\section{Materials and Methods}

\section{Study Design}

The trial was designed to be randomized, two parallel arms, double blinded, and unicentered, and it was conducted at the Conservative Dentistry Department, Outpatient Clinic of Faculty of DentistryCairo University, Egypt. The trial was reviewed and approved by the Research Ethics Committee-Faculty of Dentistry, Cairo University_in September 2018 (Approval No. 26918) and registered in the Clinical Trials Registry (number NCT03590977). Patients were recruited between January 2019 and March 2019.

\section{Sample Size Calculation}

A study by Hu et al. ${ }^{11}$ evaluated the efficacy of herbal licorice on reducing salivary S. mutans levels in high caries risk patients. The expected difference in bacterial count from pre- to posttreatment between the two groups is $2.4 \pm 2.7$. Using power 80 and $5 \%$ significance level, it was found that $n=21$ in each group was required to be able to reject the null hypothesis that the population means of the experimental and control groups are equal. This number is to be increased to 26 in each group to compensate for possible losses during follow-up.

\section{Eligibility Criteria}

Patients were recruited from Outpatient Clinic of Faculty of Dentistry-Cairo University, Egypt-with the following inclusion criteria: Participants should be from 18 to 55 years of age, males or females, good oral hygiene, patients with high caries risk identified using cardiogram model, and cooperative patients approving to participate in the study. ${ }^{12}$ The exclusion criteria excluded patients with any of the following conditions: Pregnancy, allergy to licorice or any oral care products or their ingredients, hypertension, severe medical complications, heavy smokers, xerostomia, lack of compliance, evidence of parafunctional habits, temporomandibular joint disorders, participants with severe or active periodontal disease, and participants who receive any antimicrobial agent 2 weeks prior to the study. All candidates were subjected to full examination and diagnosis to identify the eligible participants. The researchers elaborately explained the trial to all eligible participants, including the objective of the study, different procedures, safety precautions, and benefits. An informed consent in simple Arabic language was obtained from each participant prior to the initiation of the clinical trial.

\section{Randomization, Sequence Generation, Allocation Concealment, and Blinding}

A total of 52 eligible participants were randomly allocated to the two groups through an online randomization Web-based tool (https://www.random.org/). Patients were randomly divided into two groups ( $n=26$ ) according to the type of mouthwash (G): Group $\mathrm{G}_{1}$ patients used the chlorhexidine-containing mouthwash, while group $G_{2}$ patients used the innovative licorice extract-containing mouthwash. Then, each group was further subdivided into three subgroups according to the time $(T): T_{0}$ represents the baseline, $T_{1}$ represents the time immediately after mouth rinse, and $T_{2}$ represents the time 1 week after rinsing to get 78 samples from each group through 1-week test period. Random-generated numbers were placed in opaque-sealed envelopes prepared by a contributor who was not involved in the study, and the allocation sequence was concealed from the primary investigator. Study timeline from recruitment to follow-up as well as the analysis was demonstrated in CONSORT 2010 flow diagram (Flowchart 1). Whereby the patients and the operator were blinded to the intervention/control assessment methods, while assessors were not blinded, as, they assign the two types of mouthwashes to all participants.

\section{Materials Preparation}

Two types of mouthwashes were used in this study: Chlorhexidine mouthwash and innovative natural fresh licorice mouthwash. Mouthwashes were stored in unlabeled and color-coded bottles, to conceal the type of mouthwash from the patient and the operator. The active ingredient of the synthetic chlorhexidine mouthwash is chlorhexidine hydrochloride.

\section{Preparation of Innovative Licorice Extract Mouthwash}

One kilogram of licorice was obtained from the local market of herbal products in Egypt. It was authenticated in Pharmacognosy Department in Faculty of Pharmacy, Cairo University, Egypt. It was soaked in three liters of ethyl alcohol $95 \%$ for 24 hours in a sealed container at room temperature with intermittent shaking. Then, it was filtered by many layers of sterile gauze to get rid of gross ruminates, and the preparation of licorice extract mouthwash was done in the laboratory of Department of Pharmacognosy in Faculty of Pharmacy, Cairo University, Egypt. The active ingredients of the innovative natural fresh licorice mouthwash were qualitatively assessed by the pharmacist, not quantitatively, to obtain glycyrrhizin (glycyrrhizic acid), glabridin, licochalcone A, licoricidin, and licorisoflavan A. The solvent was evaporated under vacuum until the licorice has completely dried using a rotary evaporator (Rotavapor ${ }^{\oplus}$ RII, Korea) HS-3000 (Fig. 1) at $60^{\circ} \mathrm{C}$ for 5 hours. The extract was dried at room temperature and pressure until the complete evaporation of the solvent. Then the extract was grinded into powder. The resulting macerates were mixed with distilled water and hand-shaken to form the mouthwash and packed in the screw-capped bottles of $100 \mathrm{~mL}$. An amount of $1.6 \mathrm{gm}$ of the extracted powder was dissolved in $100 \mathrm{~mL}$ of the distilled water. ${ }^{13}$ Other solvents, preservatives, sweeteners, and flavoring agents were added. ${ }^{14}$ Finally, an innovative licorice mouthwash with a 
Flowchart 1: CONSORT 2010 flow diagram

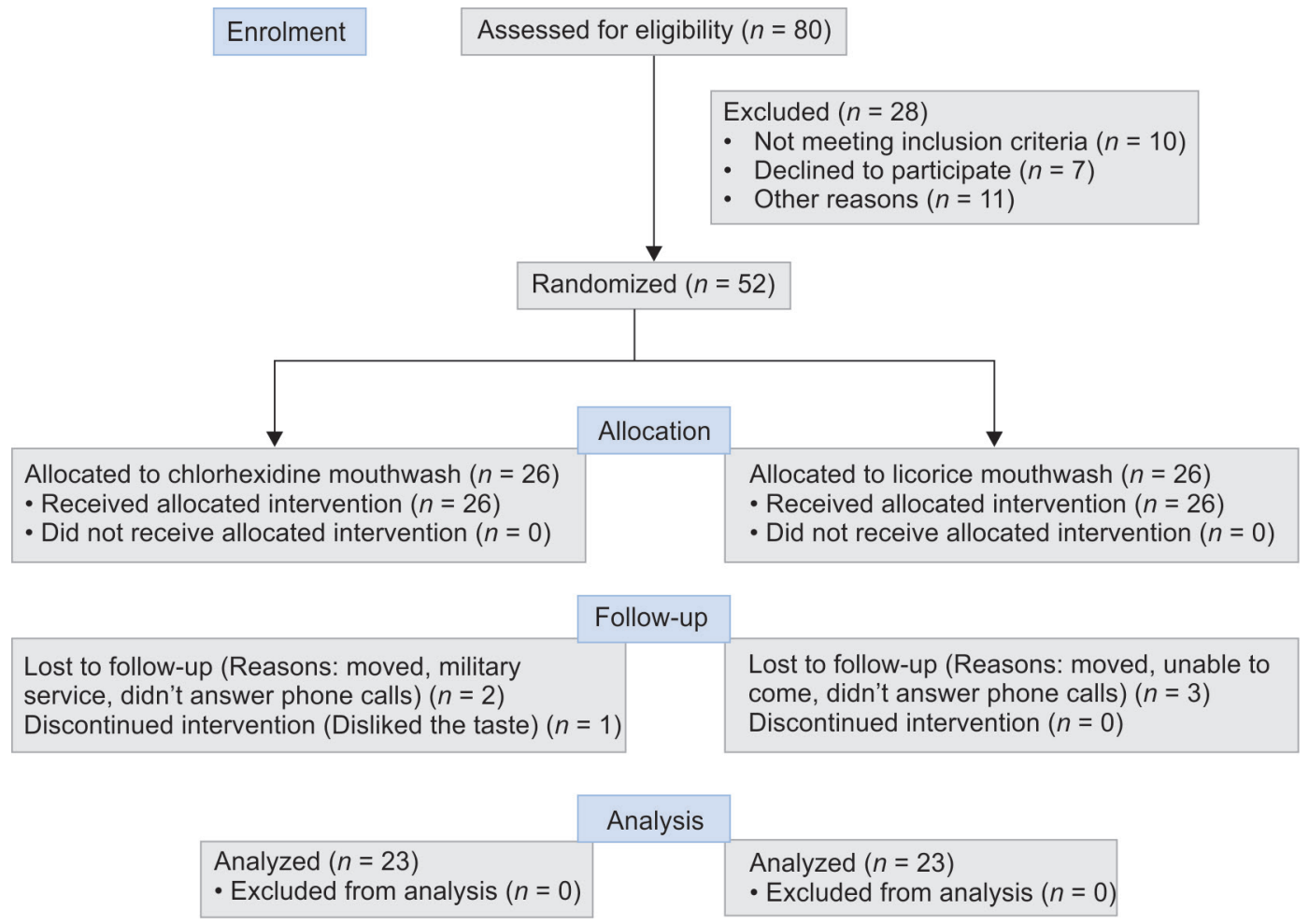

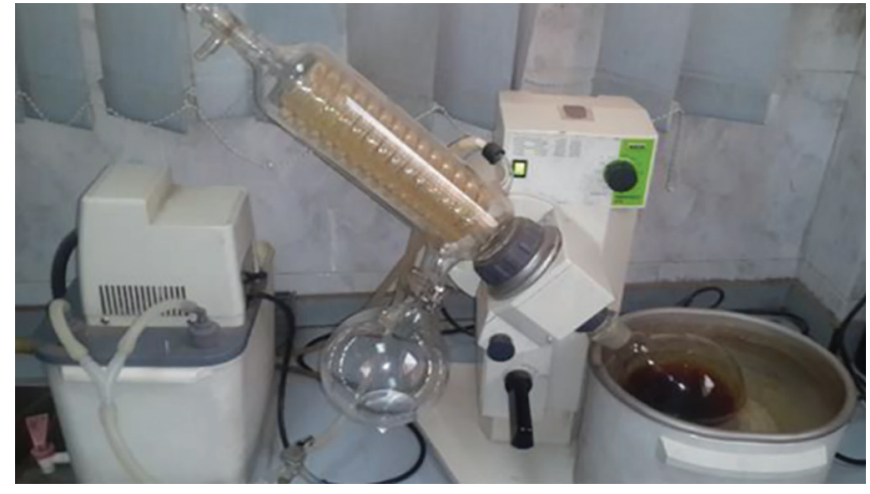

Fig. 1: Rotary evaporator machine (Rotavapor machine RII)

concentration of $16 \mathrm{mg} / \mathrm{mL}$ was prepared. The extract was stored at $-20^{\circ} \mathrm{C}$ in a tightly closed container to prevent contamination until further use.

\section{Composition of Innovative Licorice Mouthwash}

- Licorice extract $1.6 \mathrm{gm}$ ( active ingredient)

- Glycerin 5 gm (solvent)

- Propylene glycol 4 gm (solvent)

- Methylparaben $0.15 \mathrm{gm}$ (preservative)

- Saccharine sodium $0.2 \mathrm{gm}$ (sweetener)

- Menthol $0.01 \mathrm{gm}$ (flavor agent)

- Distilled water $90.64 \mathrm{gm}$

\section{Bacterial Cultivation}

Mitis salivarius agar (MSA) (Hi Media Laboratories Pvt. Ltd., India) was used for S. mutans spp. Count and MSA were supplemented with $20 \%$ sucrose, 0.2 units $/ \mathrm{mL}$ bacitracin, and $1 \%$ potassium tellurite (mitis-salivarius bacitracin) for $S$. mutans count.

\section{Mouthwash Administration and Saliva Sampling}

Patients were asked to rinse their mouth with $10 \mathrm{~mL}$ of the prepared mouthwash designated for their group 1 minute/day for 1 week (7 days continuously); then, they were instructed to spit in a labeled sterile falcon tube. Written instructions were provided to the participants, and regular follow-up was scheduled through daily phone calls. Saliva samples were collected early in the morning from each patient before, immediately after, and 1 week after. Patients were also instructed not to eat or drink anything (except water) 2 hours before saliva collection to minimize possible food debris and stimulation of saliva. The patients were instructed not to brush their teeth on the day of sampling and to follow their regular diet intake. Patients were also instructed not to use any other antimicrobial agents after an intervention. ${ }^{8}$ The test tubes containing the saliva samples were transferred immediately to the Microbiology Department-Cairo University-for the microbial analysis. The tubes were labeled with nonidentifiable numbers to ensure blinding of the microbiologist.

\section{Microbiological Analysis}

The salivary samples in the test tubes were vortexed for 1 minute and then were serially diluted to $10^{3}, 10^{4}$, and $10^{5}$. The tubes were vigorously shaken for 30 seconds on vortex (Assistent Reamix 2789 Vortex Mixer, Medical Trade Center, Hamburg, Germany) to obtain homogenous distribution. Afterward, $100 \mu \mathrm{L}$ of each dilution were spread using micropipette from the tube to the agar medium and spread onto the surface of the agar using a sterile glass rod to give homogenous bacterial growth. S. mutans was activated on MSA. Each plate was prepared to detect the inhibition zone 
depending on the inhibition zone size; the effect of antimicrobial activity was estimated as minimal inhibitory concentration $(1.25 \mathrm{mg} / \mathrm{mL}){ }^{15}$ Finally, the MSA plates were multiplied in an atmosphere of $5 \% \mathrm{CO}_{2}$ inside the candle jar for 24 hours. Then, the jar was immediately closed tightly and placed in the incubator (Precision dual illuminated program, Germany). The bacterial count was obtained at baseline, immediately after and after 1 week for both groups as in Figures 2 and 3.

\section{pH Measurement}

The $\mathrm{pH}$ of the collected saliva was measured immediately to avoid any time-based $\mathrm{pH}$ changes by digital portable $\mathrm{pH}$-meter Adwa (AD-11) (Adwa Kft.Alsó-Kikötö sor 11.C6726 Szeged, Hungary), ${ }^{16}$ as it gives more accurate results than the $\mathrm{pH}$ strips. ${ }^{17}$

\section{Evaluation of Plaque Index}

The oral hygiene and plaque amount were estimated using a mirror and graduated periodontal probe in accordance with Silness and Löe plaque index, which assessed the amount of plaque in the cervical part of the tooth. The four surfaces of each tooth except the wisdom tooth were examined (buccal, lingual, and proximal) and scored according to Silness and Löe plaque index system. ${ }^{12}$

\section{Statistical Analysis}

Categorical data were presented as frequencies and analyzed using a Chi-square test. Numerical data were tested using Shapiro-Wilk test and presented as mean and standard deviation values. Parametric data (bacterial count) were analyzed using an independent $t$-test for intergroup comparisons and one-way repeated measures ANOVA followed by Bonferroni post hoc test for intragroup comparisons. Nonparametric data (salivary $\mathrm{pH}$ and plaque index) were analyzed using Mann-Whitney $U$ test for intergroup comparisons and Friedman's test of repeated measures followed by multiple pairwise comparisons utilizing Wilcoxon signed-rank with Bonferroni test for intragroup comparisons. Spearman's rank-order correlation coefficient was used to analyze different correlations. The significance level was determined at $p \leq 0.05$ for all tests.

\section{Results}

\section{Demographic Data}

According to the sample size calculations, 42 participants were required for this trial, and the number was increased to 52 to compensate for the loss of follow-up. Therefore, a total of 52 participants were recruited at the beginning of the trial. Cases were
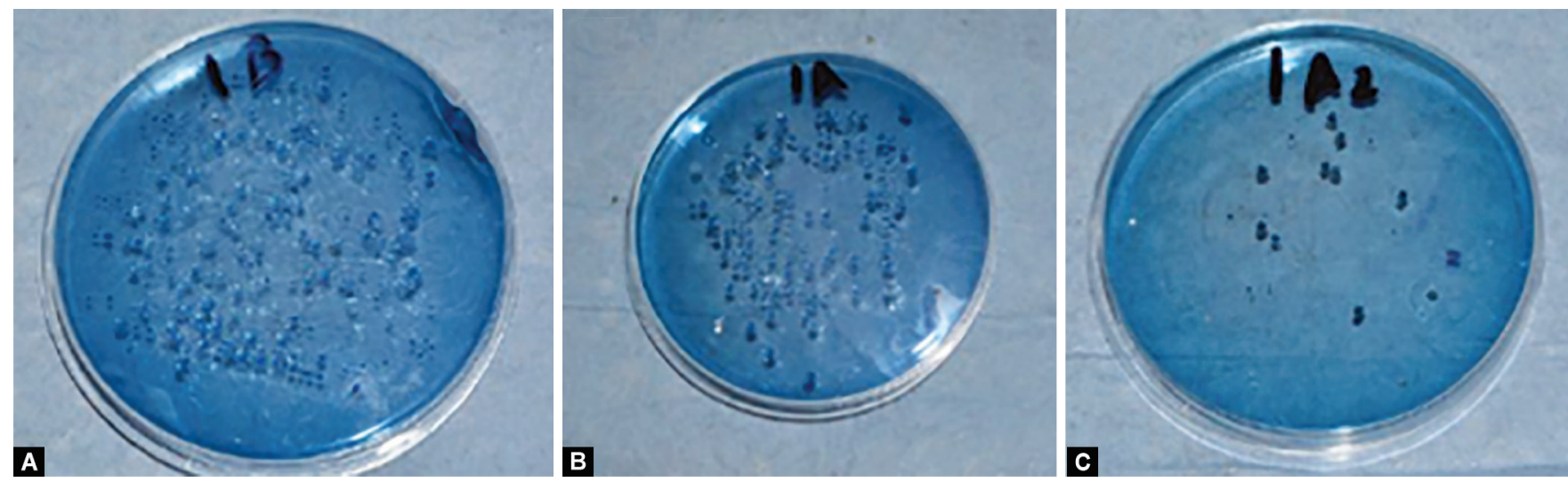

Figs 2 A to C: (A) Agar base plate containing S. mutans colonies before chlorhexidine mouthwash; (B) Agar base plate containing S. mutans colonies immediately after chlorhexidine mouthwash; (C) Agar base plate containing S. mutans colonies after 1 week of chlorhexidine mouthwash
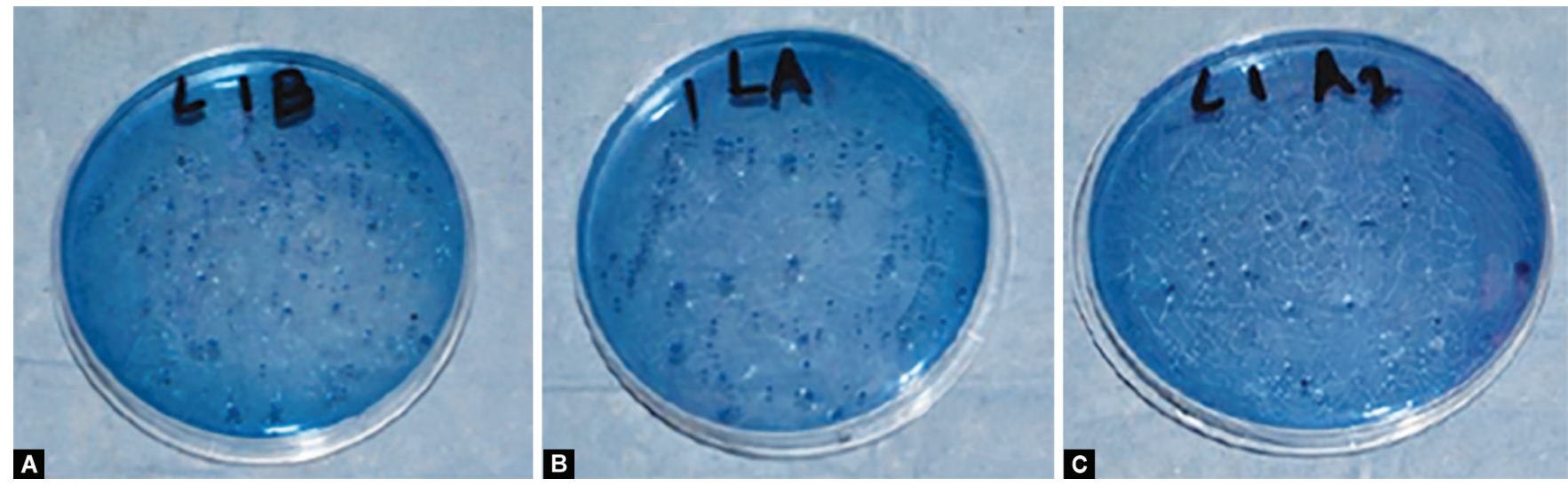

Figs 3 A to C: (A) Agar base plate containing S. mutans colonies before licorice mouthwash; (B) Agar base plate containing S. mutans colonies immediately after licorice mouthwash; (C) Agar base plate containing S. mutans colonies after 1 week of licorice mouthwash 
equally and randomly allocated to the test and the control groups (i.e., 26 cases each). Six participants discontinued the intervention during the different follow-up periods. Female participants in both groups constituted $56.6 \%$, while $43.5 \%$ were males. The mean age of the participants in the control group was $31.65 \pm 9.61$, and it was $34.04 \pm 11.15$ in the test group. There were no significant differences between both groups regarding sex $(p=1)$ and age $(p=0.440)$ of the participants.

\section{Bacterial Count}

Regarding intergroup comparison, there was no statistically significant difference between the two mouthwashes at baseline, immediately after, and after 1 week at $p=0.467, p=0.554$, and $p=0.393$, respectively, as listed in Table 1 . As for intragroup comparison, there was a statistically significant difference between values measured at different follow-up intervals. The highest value was reported at baseline, followed by the value measured immediately after application, while the lowest value was found after 1 week of application for both groups $(p<0.001)$ (Table 1$)$.

\section{Percentage Change (\%) in Bacterial Count}

There was no statistically significant difference between the two mouthwashes at baseline, immediately after, and after 1 week at $p=0.889, p=0.618$, and $p=0.631$, respectively. The highest statistically significant difference was found between baseline-1 week, followed by the difference between baseline and immediately after application-while the lowest difference was found between after application and 1 week. Pairwise comparisons showed the difference between baseline and 1 week to be significantly higher than the percentages of other differences $(p<0.001)$ for both groups (Table 1).

\section{Salivary pH Effect}

Regarding intergroup comparison, there was no significant difference between both groups at the baseline and after 1 week at $p=0.950$ and $p=0.083$, respectively. However, a statistically significant difference was found immediately after for both groups $(p<0.001)$ as represented in Table 2 . Regarding intragroup comparison, a statistically significant difference was found at different time intervals of $\mathrm{G}_{1}$; the highest value was found at baseline, and the lowest value was found immediately after application $(p<0.001)$. For $\mathrm{G}_{2}$, there was a highly statistically significant difference found immediately after application, while the lowest after 1 week of application $(p<0.001)$ (Table 2).

\section{Percentage Change (\%) in Salivary pH Scores}

There was no significant difference between both groups at the baseline and immediately after application at $p=0.322$ and $p=0.335$, respectively, as represented in Table 2 . After 1 week of application, a statistically significant difference found in $G_{1}$ was

Table 1: Mean and standard deviation (SD) values for bacterial count and percentage change (\%)

\begin{tabular}{|c|c|c|c|c|}
\hline \multirow[b]{2}{*}{ Time } & \multicolumn{2}{|c|}{ Mean $\pm S D$} & \multirow[b]{2}{*}{ Difference $(95 \% \mathrm{Cl})$} & \multirow[b]{2}{*}{$p$ value } \\
\hline & Control & Test & & \\
\hline Baseline & $280.87 \pm 94.05^{a}$ & $257.83 \pm 117.63^{a}$ & $23.04(-40.33: 86.41)$ & $0.467 \mathrm{~ns}$ \\
\hline Immediately after & $141.30 \pm 66.49^{b}$ & $129.35 \pm 69.39^{b}$ & $11.95(-28.43: 52.34)$ & $0.554 \mathrm{~ns}$ \\
\hline \multirow[t]{2}{*}{ After 1 week } & $86.30 \pm 27.64^{c}$ & $78.26 \pm 35.12^{c}$ & $8.04(-10.76: 26.85)$ & $0.393 \mathrm{~ns}$ \\
\hline & \multicolumn{2}{|c|}{ Mean $\pm S D$} & & \\
\hline Difference (\% change) & Control & Test & Difference $(95 \% \mathrm{Cl})$ & pvalue \\
\hline Baseline-immediately after & $49.54 \pm 14.66^{b}$ & $50.07 \pm 10.68^{b}$ & $-0.53(-8.17: 7.11)$ & $0.889 \mathrm{~ns}$ \\
\hline Immediately after-1 week & $35.06 \pm 19.95^{b}$ & $37.80 \pm 16.86^{b}$ & $-2.73(-13.72: 8.25)$ & $0.618 \mathrm{~ns}$ \\
\hline Baseline-1 week & $67.64 \pm 11.14^{\mathrm{a}}$ & $69.11 \pm 9.37^{a}$ & $-1.46(-7.59: 4.65)$ & $0.631 \mathrm{~ns}$ \\
\hline$p$-value & $0.001^{*}$ & $0.001^{*}$ & & \\
\hline
\end{tabular}

Different superscript letters indicate a statistically significant difference within the same vertical column. $\mathrm{Cl}$, confidence interval for mean difference; ${ }^{*}$ Significant $(p \leq 0.001)$; ns, nonsignificant $(p>0.001)$

Table 2: Mean and standard deviation (SD) values for salivary pH scores and percentage change (\%)

\begin{tabular}{|c|c|c|c|c|}
\hline \multirow[b]{2}{*}{ Time } & \multicolumn{2}{|c|}{ Mean $\pm S D$} & \multirow[b]{2}{*}{ Difference (95\% Cl) } & \multirow[b]{2}{*}{ pvalue } \\
\hline & Control & Test & & \\
\hline Baseline & $7.68 \pm 0.52^{a}$ & $7.67 \pm 0.41^{b}$ & $0.009(-0.27: 0.28)$ & $0.950 \mathrm{~ns}$ \\
\hline Immediately after & $7.36 \pm 0.61^{\mathrm{b}}$ & $8.08 \pm 0.37^{\mathrm{a}}$ & $-0.72(-1.02:-0.42)$ & $<0.001^{*}$ \\
\hline \multirow[t]{2}{*}{ After 1 week } & $7.40 \pm 0.46^{\mathrm{ab}}$ & $7.62 \pm 0.39^{b}$ & $-0.22(-0.47: 0.03)$ & $0.083 \mathrm{~ns}$ \\
\hline & \multicolumn{2}{|c|}{ Mean $\pm S D$} & & \\
\hline Difference & Control & Test & Difference $(95 \% \mathrm{Cl})$ & pvalue \\
\hline Baseline-immediately after & $7.44 \pm 3.53^{\mathrm{a}}$ & $6.33 \pm 4.00^{\mathrm{a}}$ & $1.11(-1.12: 3.35)$ & $0.322 \mathrm{~ns}$ \\
\hline Immediately after-1 week & $5.66 \pm 4.87^{\mathrm{a}}$ & $6.92 \pm 3.82^{\mathrm{a}}$ & $-1.25(-3.86: 1.34)$ & $0.335 \mathrm{~ns}$ \\
\hline Baseline-1 week & $6.31 \pm 4.59^{\mathrm{a}}$ & $3.13 \pm 2.68^{b}$ & $3.17(0.92: 5.42)$ & $0.007^{*}$ \\
\hline$p$-value & $0.001^{*}$ & $0.001^{*}$ & & \\
\hline
\end{tabular}

Different superscript letters indicate a statistically significant difference within the same vertical column. $\mathrm{Cl}$, confidence interval for mean difference; ${ }^{*}$ Significant $(p \leq 0.001)$; ns, nonsignificant $(p>0.001)$ 
higher than that found in $\mathrm{G}_{2}(p=0.007)$. There was no significant difference between values measured at different time points for $G_{1}$ $(p=0.315)$. However, there was a significant difference between values measured at different time points for $\mathrm{G}_{2}(p<0.001)$. The highest difference was found between immediately after application and after 1 week, while the lowest difference was found between baseline and 1 week for $G_{2}$. Pairwise comparisons showed the difference between baseline and 1 week to be significantly lower than the percentages of other differences $(p<0.001)$ for $\mathrm{G}_{2}$ (Table 2).

\section{Plaque Index}

Regarding intergroup comparison, no significant difference was noticed between both groups at the baseline ( $p=0.119)$; however, there was a higher significant difference noticed with $\mathrm{G}_{2}$ immediately after application and after 1 week of application than $\mathrm{G}_{1}(p<0.001)$ as represented in Table 3. Regarding intragroup comparison, the highest significant difference was found at baseline, followed by the value measured immediately after application, while the lowest was found after 1 week of application for both groups $(p<0.001)$ (Table 3$)$.

\section{Percentage Change (\%) in Plaque Index}

There was a statistically significant difference found between $G_{1}$ and $G_{2}$ at different time intervals $(p<0.05)$. The highest statistical difference was found between baseline and after 1 week, followed by the difference between immediately after application and 1 week, while the lowest difference was found between baseline and immediately after application for both groups ( $p<0.001$ ) (Table 3 ).

There was a positive weak correlation between bacterial count and plaque index, which was statistically significant $(p<0.001)$ as represented in Table 4.

\section{Discussion}

The conventional antimicrobial regimes for controlling dental caries include the generalized killing of oral bacteria with antibacterial products or mechanical removal of dental plaque. ${ }^{18}$ The level of S. mutans in patients with high caries risk is considered one of the most important risk factors besides salivary $\mathrm{pH}$, flow, and buffer in addition to plaque index. Most of the available caries preventive regimes contain synthetic mouthwash that has proven its efficacy against the oral pathogen in the high caries risk population.
Chlorhexidine is the gold standard chemoprophylactic agent advocated in caries preventive protocols for high caries patients. However, its side effects remained controversial and prohibited its use. ${ }^{19,20}$ Licorice is a natural and safe root herbal extract of phytochemicals derived from plants, and it demonstrated specific antibacterial activity reducing oral $S$. mutans levels and can be an economical alternative to synthetic antimicrobial agents, which led to a rise in treating diseases of the oral cavity. ${ }^{21,22}$

Due to its sweet taste, licorice has been used worldwide as a sweetener and a flavoring agent in food and medicine production and is listed by the Food and Drug Administration in the USA as generally recognized as safe. According to WHO, $100 \mathrm{mg} /$ day of licorice can be safely consumed without any side effects, while Touyz ${ }^{23}$ recommended that $250-500 \mathrm{mg}$ of licorice can be safely used up to three times per day for medicinal purposes. In the present study, an innovative licorice mouthwash preparation of $160 \mathrm{mg} /$ day was instructed to patients in the intervention group for 1 week with no adverse effects detected. Chlorhexidine mouth rinse was used as a comparator to the test group as it is the gold standard, commercially and widely available rinses due to its broadspectrum antimicrobial activity. ${ }^{20}$

In the present study, bacterial count, salivary $\mathrm{pH}$, and plaque index were assessed. Licorice mouthwash showed a reduction in the bacterial count after 1 week of application in agreement with in vivo studies by Almaz et al., ${ }^{5}$ Peters et al., ${ }^{9}$ and Mentes et al., ${ }^{24}$ who showed that there was a marked decline in the number of

Table 4: Correlation between bacterial count, salivary $\mathrm{pH}$, and plaque index

\begin{tabular}{|c|c|c|}
\hline Variable & $r_{s}$ & $p$ value \\
\hline $\begin{array}{l}\text { Bacterial count } \\
\text { Plaque index }\end{array}$ & 0.415 & $<0.001^{*}$ \\
\hline Variable & $r_{s}$ & $p$ value \\
\hline $\begin{array}{l}\text { Bacterial count } \\
\text { Salivary pH }\end{array}$ & 0.041 & $0.635 \mathrm{~ns}$ \\
\hline Variable & $r_{\mathrm{s}}$ & $p$ value \\
\hline $\begin{array}{l}\text { Salivary pH } \\
\text { Plaque index }\end{array}$ & 0.148 & $0.083 \mathrm{~ns}$ \\
\hline
\end{tabular}

Table 3: Mean and standard deviation (SD) values for plaque index and percentage change (\%)

\begin{tabular}{|c|c|c|c|c|}
\hline \multirow[b]{2}{*}{ Time } & \multicolumn{2}{|c|}{ Mean $\pm S D$} & \multirow[b]{2}{*}{ Difference $(95 \% \mathrm{Cl})$} & \multirow[b]{2}{*}{ pvalue } \\
\hline & Control & Test & & \\
\hline Baseline & $1.91 \pm 0.73^{a}$ & $2.26 \pm 0.75^{\mathrm{a}}$ & $-0.34(-0.78: 0.09)$ & $0.119 \mathrm{~ns}$ \\
\hline Immediately after & $0.65 \pm 0.65^{b}$ & $1.78 \pm 0.74^{b}$ & $-1.13(-1.54:-0.71)$ & $<0.001^{*}$ \\
\hline After 1 week & $0.22 \pm 0.52^{b}$ & $1.17 \pm 0.83^{c}$ & $-0.957(-1.37:-0.54)$ & $<0.001^{*}$ \\
\hline & \multicolumn{2}{|c|}{ Mean $\pm S D$} & & \\
\hline Difference & Control & Test & Difference $(95 \% \mathrm{Cl})$ & pvalue \\
\hline Baseline-immediately after & $67.39 \pm 33.14^{b}$ & $18.84 \pm 23.19^{b}$ & $48.55(31.49: 65.60)$ & $<0.001^{*}$ \\
\hline Immediately after-1 week & $80.77 \pm 38.40^{a}$ & $45.65 \pm 38.67^{\mathrm{a}}$ & $35.11(7.61: 62.61)$ & $0.014^{*}$ \\
\hline Baseline-1 week & $92.03 \pm 18.71^{a}$ & $52.17 \pm 31.90^{\mathrm{a}}$ & $39.85(24.20: 55.50)$ & $<0.001^{*}$ \\
\hline$p$-value & $0.001^{*}$ & $0.001^{*}$ & & \\
\hline
\end{tabular}

Different superscript letters indicate a statistically significant difference within the same vertical column. $\mathrm{Cl}$, confidence interval for mean difference; ${ }^{*}$ Significant $(p \leq 0.001)$; ns, nonsignificant $(p>0.001)$ 
S. mutans oral bacteria. Ahn et al. ${ }^{25}$ isolated three antimicrobial flavonoids, named 1 methoxyficifolinol, licorisoflavan $A$, and 6,8-diprenylgenistein isolated from licorice extract, which exhibited complete inhibition of the formation of biofilm and recommended the use of these flavonoids may be useful alternatives to chlorhexidine. Jain et al. ${ }^{8}$ observed that alcohol is a better solvent than water due to its polar nature, which resulted in the leaching of more active ingredients during extraction. In contrast, a pilot study that assumed tooth brushing with a licorice gel containing $2.5 \%$ licorice herbal extract reported no difference in the bacterial count or plaque index because the inhibition of S. mutans adhesion by the effect of glycyrrhizin of licorice was masked by the negative effects of sucrose in starch licorice-containing gel. ${ }^{26}$

Furthermore, chlorhexidine mouthwash group revealed lower bacterial counts after 1 week of application that explained chlorhexidine is charged positively and has a high attraction for negative ions found in cell membranes of Streptococcus bacteria. ${ }^{15}$ It provoked condensation of cytoplasmic protein and nucleic acid and got rid of the function of phosphoenolpyruvatephosphotransferase sugar transportation system; thus, it arrested the acid production in oral streptococcal bacteria. However, Jain et al. ${ }^{8}$ and Öznurhan et al. ${ }^{10}$ reported that chlorhexidine had some hazards, for example, increased risk of caries due to fermentation and alcohol content, metallic taste, staining of teeth, and cytotoxic effects on cells opposite to licorice mouthwash that has no oral side effects as confirmed in the previous study. ${ }^{6}$

For salivary $\mathrm{pH}$ scores, the licorice mouthwash group showed the highest value immediately after application and back to normal after 1 week. This was in accordance with Jain et al. ${ }^{8}$ and Khairnar et al. ${ }^{27}$ who considered licorice as an alkaline natural herb with organoleptic properties stimulating the salivary flow due to the stimulation of the parotid gland. Due to a greater concentration of bicarbonate ions in stimulated saliva, it increased the buffering capacity raising $\mathrm{pH}$ values. Moreover, it had the ability to clear up acids, improve $\mathrm{pH}$, and subsequently stimulate saliva leading to increasing resistivity to caries. This was in disagreement with Qinna et al. ${ }^{28}$ who demonstrated that licorice shifted $\mathrm{pH}$ values toward acidity due to the presence of glycyrrhizic acid, which is the active ingredient of licorice herbal extract and promotes its $\mathrm{pH}$ drop.

Chlorhexidine mouthwash showed the lowest values for salivary $\mathrm{pH}$ scores found immediately after application than higher values after 1 week of application. This was in agreement with Jain et al. $^{8}$ who showed that chlorhexidine led to a drop in $\mathrm{pH}$ of immediate postrinse salivary samples explaining that chlorhexidine was neutral originally and due to the absence of flavonoids.

There was a significant difference between the values measured at different follow-up intervals regarding plaque index after licorice mouthwash in agreement with Kumar et al. ${ }^{29}$ who reported that licorice herbal mouthwash was a safe and natural replacement to synthetic chlorhexidine mouthwash with respect to its clinical hazards, safety, and taste alteration. Other studies found that licorice herbal extract had strong antiadhesive activity against Porphyromonas gingivalis plaque pathogen, preventing the production of matrix metalloproteinase in periodontal diseases acting like antibiotic doxycycline action..$^{30,31}$

There was a positive weak correlation between bacterial count and plaque index, which was statistically significant and in agreement with the results reported by Yamashita et al. ${ }^{32}$ who reported that the presence of biofilm was a good candidate for the growth of oral bacteria.
Herbal preparations are safe to use as a mouthwash; also, their systematic availability in traces does not cause any adverse clinical hazards. ${ }^{7,33,34}$ Therefore, the application of antimicrobial agents in the oral cavity might inhibit the growth of microorganisms and subsequently prevent the development of dental caries. The most common anticariogenic oral mouthwashes are chlorhexidine and fluoride. Mouthwashes prepared from herbal natural extracts are considered very promising as they are effective, yet less toxic than the most widely used pharmaceutical mouthwashes. ${ }^{31}$

\section{ConClusion}

Under the limitations of the current study, it can be concluded that, in high caries risk patients, there was no significant difference between licorice and chlorhexidine mouthwashes regarding Streptococcus bacterial count. Consequently, licorice mouthwash could be a suitable alternative to the current synthetic mouthwashes. Licorice mouthwash stimulates salivary flow and thus raises salivary $\mathrm{pH}$ in high caries risk patients. Chlorhexidine remains the gold standard in reducing dental plaque index. There was a positive weak correlation between bacterial count and plaque index.

\section{Clinical Significance}

Natural herbal mouthwash may be incorporated in dental preventive measures, such as toothpastes or mouthwashes to be used as cavity-fighting compound with minimum hazards as a substitute to the present available synthetic preventive measures. Further clinical studies are recommended to confirm these results and to determine the proper dose and duration of natural herbal extracts against oral pathogens.

\section{Recommendations}

The adoption of clinical protocols should be based on scientific evidence to use natural herbal preventive measures as an alternative to the present preventive strategy.

\section{References}

1. Kassebaum NJ, Bernabé E, Dahiya M, et al. Global burden of untreated caries: a systematic review and metaregression. J Dent Res 2015;94(5):650-658. DOI: 10.1177/0022034515573272.

2. Abbass MM, Mahmoud SA, El Moshy S, et al. The prevalence of dental caries among Egyptian children and adolescents and its association with age, socioeconomic status, dietary habits and other risk factors. A cross-sectional study. F1000 Res 2019;8(8):1-9. DOI: 10.12688/ f1000research.17047.1

3. Ozer S, Sen Tunc E, Bayrak S, et al. Evaluation of certain risk factors for early childhood caries in Samsun, Turkey. Eur J Paediatr Dent 2011;12(2):103-106. PMID: 21668281.

4. Chung JY, Choo JH, Lee MH, et al. Anticariogenic activity of macelignan isolated from Myristica fragrans (nutmeg) against Streptococcus mutans. Phytomedicine 2006;13(4):261-266. DOI: 10.1016/j.phymed.2004.04.007.

5. Almaz ME, Sönmez IŞ, Ökte Z, et al. Efficacy of a sugar-free herbal lollipop for reducing salivary Streptococcus mutans levels: a randomized controlled trial. Clin Oral Investig 2017;21(3):839-845. DOI: 10.1007/s00784-016-1827-y.

6. Messier C, Epifano F, Genovese S, et al. Licorice and its potential beneficial effects in common oro-dental diseases. Oral Dis 2012;18(1):32-39. DOI: 10.1111/j.1601-0825.2011.01842.x.

7. Kwon YJ, Son DH, Chung TH, et al. A review of the pharmacological efficacy and safety of licorice root from corroborative clinical trial findings. J Med Food 2020;23(1):12-20. DOI: 10.1089/jmf.2019.4459. 
8. Jain E, Pandey RK, Khanna R. Licorice root extracts as potent cariostatic agents in pediatric practice. J Indian Soc Pedod Prev Dent 2013;31(3):146-152. DOI: 10.4103/0970-4388.117964.

9. Peters MC, Tallman JA, Braun TM, et al. Clinical reduction of S. Streptococcus mutans in pre-school children using a novel licorice root extract lollipop: a pilot study. Eur Arch Paediatr Dent 2010;11(6): 274-278. DOI: 10.1007/BF03262762.

10. Öznurhan F, Buldur B, Cart Ö, et al. Antimicrobial efficacy of chlorhexidine and licorice mouthwashes in children. Med Dent $J$ 2019;20(1):13-20. DOI: 10.4274/meandros.galenos.2018.79663.

11. $\mathrm{Hu} \mathrm{CH}, \mathrm{He}$ J, Eckert R, et al. Development and evaluation of a safe and effective sugar-free herbal lollipop that kills cavity-causing bacteria. Int J Oral Sci 2011;3(1):13-20. DOI: 10.4248/IJOS11005.

12. Almosa NA, Lundgren T, Al-Mulla A, et al. Caries risk profiles in orthodontic patients: a 4-year follow-up study using the Cariogram model in governmental vs. private clinics. Saudi Dent J 2018;30(2):166-174. DOI: 10.1016/j.sdentj.2018.02.001.

13. Yu IC, Tsai YF, Fang JT, et al. Effects of mouthwash interventions on xerostomia and unstimulated whole saliva flow rate among hemodialysis patients: a randomized controlled study. Int J Nurs Stud 2016;63:9-17. DOI: 10.1016/j.ijnurstu.2016.08.009.

14. Rowe RC, Sheskey P, Quinn M. Handbook of pharmaceutical excipients. 6th ed. Libros Digitales-Pharmaceutical Press; 2009; p. 1-917.

15. Malvania EA, Sharma AS, Sheth SA, et al. In vitro analysis of licorice (Glycyrrhiza glabra L) root extract activity on Streptococcus mutans in comparison to chlorhexidine and fluoride mouthwash. J Contemp Dent Pract 2019;20(12):1389-1394. PMID: 32381838.

16. Mohammadi SN, Prashant GM, Kumar PN, et al. Effect of different sugar free flavoured chewing gums on salivary $\mathrm{pH}$-a double blinded, parallel arm randomized clinical trial. J Adv Med Med Res 2016;13(3):1-6. DOI: 10.9734/bjmmr/2016/23388.

17. Kumar S, Sogi SH, Indushekar KR. Comparative evaluation of the effects of xylitol and sugar-free chewing gums on salivary and dental plaque $\mathrm{pH}$ in children. J Indian Soc Pedod Prev Dent 2013;31(4): 240-244. DOI: 10.4103/0970-4388.121822.

18. Ajagannanavar SL, Battur $\mathrm{H}$, Shamarao $\mathrm{S}$, et al. Effect of aqueous and alcoholic licorice (Glycyrrhiza glabra L) root extract against Streptococcus mutans and lactobacillus acidophilus in comparison to chlorhexidine: an in vitro study. J Int Oral Health 2014;6(4):29-34. PMID: 25214729. PMCID: PMC4148569.

19. Becerik $S$, Türkoğlu $O$, Emingil $G$, et al. Antimicrobial effect of adjunctive use of chlorhexidine mouthrinse in untreated gingivitis: a randomized, placebo-controlled study. APMIS 2011;119(6):364-372. DOI: 10.1111/j.1600-0463.2011.02741.x.

20. Thomas A, Thakur SR, Shetty SB. Anti-microbial efficacy of green tea and chlorhexidine mouth rinses against Streptococcus mutans, Lactobacilli spp. and Candida albicans in children with severe early childhood caries: A randomized clinical study. J Indian Soc Pedod Prev Dent 2016;34(1):65-70. DOI: 10.4103/0970-4388.175518.
21. Ghezzi EM. Developing pathways for oral care in elders: evidencebased interventions for dental caries prevention in dentate elders. Gerodontology 2014;31(1):31-36. DOI: 10.1111/ger.12081.

22. Sidhu P, Shankargouda S, Rath A, et al. Therapeutic benefits of licorice in dentistry. J Ayurveda Integr Med 2020;11(1):82-88. DOI: 10.1016/j. jaim.2017.12.004.

23. Touyz LZ. Licorice health check, Oro-dental implications, and a case report. Case Rep Med 2009;1-6:170735. DOI: 10.1155/2009/170735.

24. Mentes JC, Kang S, Spackman S, et al. Can a licorice lollipop decrease cariogenic bacteria in nursing home residents? Res Gerontol Nurs 2012;5(4):233-237. DOI: 10.3928/19404921-20120906-07.

25. Ahn SJ, Park SN, Lee YJ, et al. In vitro antimicrobial activities of 1-methoxyficifolinol, licorisoflavan A, and 6,8-diprenylgenistein against Streptococcus mutans. Caries Res 2015;49(1):78-89. DOI: 10.1159/000362676.

26. Söderling $E$, Karjalainen S, Lille M, et al. The effect of licorice extractcontaining starch gel on the amount and microbial composition of plaque. Clin Oral Investig 2006;10(2):108-113. DOI: 10.1007/s00784006-0040-9.

27. Khairnar MR, Dodamani AS, Karibasappa GN, et al. Efficacy of herbal toothpastes on salivary $\mathrm{pH}$ and salivary glucose - a preliminary study. J Ayurveda Integr Med 2017;8(1):3-6. DOI: 10.1016/j.jaim.2016.12.004.

28. Qinna NA, Mallah EM, Arafat TA, et al. Effect of licorice and grapefruit juice on paracetamol pharmacokinetics in human saliva. Int J Pharm Pharm Sci 2012;4(4):158-162.

29. Kumar $\mathrm{P}, \mathrm{Ansari} \mathrm{SH}$, Ali J. Herbal remedies for the treatment of periodontal disease - a patent review. Recent Pat Drug Deliv Formul 2009;3(3):221-228. DOI: 10.2174/187221109789105603.

30. Farhad SZ, Aminzadeh A, Mafi M, et al. The effect of adjunctive lowdose doxycycline and licorice therapy on gingival crevicular fluid matrix metalloproteinase-8 levels in chronic periodontitis. Dent Res J (Isfahan) 2013;10(5):624. PMID: 24348620. PMCID: PMC3858737.

31. Bhadoria N, Gunwal MK, Suryawanshi H, et al. Antiadherence and antimicrobial property of herbal extracts (Glycyrrhiza glabra $\mathrm{L}$ and Terminalia chebula) on Streptococcus mutans: an in vitro experimental study. J Oral Maxillofac Pathol 2019;23(1):73-77. DOI: 10.4103/jomfp. JOMFP_103_18.

32. Yamashita $T$, Kawada-Matsuo M, Katsumata $T$, et al. Antibacterial activity of disodium succinoyl glycyrrhetinate, a derivative of glycyrrhetinic acid against Streptococcus mutans. Microbiol Immunol 2019;63(7):251-260. DOI: 10.1111/1348-0421.12717.

33. Bajaj N, Tandon S. The effect of Triphala and Chlorhexidine mouthwash on dental plaque, gingival inflammation, and microbial growth. Int J Ayurveda Res 2011;2(1):29-36. DOI: 10.4103/09747788.83188.

34. De Oliveira Carvalho I, Purgato GA, Píccolo MS, et al. In vitro anticariogenic and antibiofilm activities of toothpastes formulated with essential oils. Arch Oral Biol 2020;117:104834. DOI: 10.1016/j. archoralbio.2020.104834. 